\title{
Responsabilidade social e educação em design: autonomia frente à complexidade dos fenômenos humanos na contemporaneidade
}

Caroline de Cerqueira Medeiros é raduada em Design pela PUC-Goiás, atualmente cursa o mestrado em Design pela Universidade de Brasília, onde pesquisa educação em design e pedagogia do design na linha de pesquisa Design, Espaço e Mediações. Tem experiência na área de design, com ênfase em design gráfico atuando principalmente com mídias sociais e design editorial. É membro do grupo de pesquisa Design Educação. <carolinemedeiros.design@gmail.com> ORCID: 0000-0003-0897-1242
Resumo Este trabalho aborda a responsabilidade social em diálogo com a educação em design como um possível caminho para que o aluno desenvolva a autonomia necessária para resolver os problemas complexos que emergem da contemporaneidade. Examina-se habilidades necessárias ao designer que compreende sua ação e seu papel ativo como sujeito neste contexto, através de revisão bibliográfica. Salienta-se a habilidade de lidar com as incertezas e complexidade do mundo, observando a subjetividade implicada no processo de design, a dinamicidade dos sistemas abertos, o processo dialógico e polissêmico em processos colaborativos de design no contexto de inovação social, exercitando a empatia e afetividade. Compreende-se que a responsabilidade social, assumida por parte do aluno de design, traz consigo a transformação pessoal, abertura ao diferente e capacidade de escuta ativa em qualquer ambiente. A inevitabilidade da transdisciplinaridade na educação em design é uma constatação e o estímulo a estudantes ocuparem posições de decisão nos processos pedagógicos é visto como catalizador destes aprendizados.

Palavras chave Responsabilidade social, Educação, Design, Autonomia, Complexidade. 
Marisa Cobbe Maass é professora do Departamento de Design da Universidade da Brasília desde o ano 2000 e Pesquisadora no PPG Design desde 2013, atuando na linha de pesquisa Design, Espaço e Mediações. Graduada em Arquitetura e Urbanismo, mestre em Teoria e História pela UnB e Doutora em Estética do Design, com estágio na Universidade de Paris 1, Sorbonne. Concluiu o Pós-doutoramento no Núcleo de Educação Artística, do Centro de Investigação em Artes e Design e Sociedade na Belas Artes da Universidade do Porto em 2017. Lidera o Grupo de Pesquisa Design Educação desde 2017.<mmaass@unb.br>

ORCID: 0000-0001-7640-9927

\section{Social responsibility and design education: autonomy in the face of the complexity of contemporary human phenomena}

Abstract This work addresses social responsibility in dialogue with design education as a possible way for the student to develop the necessary autonomy to solve the complex problems that emerge from contemporary times. Skills necessary for the designer who understands his action and his active role as a subject in this context are examined, through bibliographic review. The ability to deal with the uncertainties and complexity of the world is emphasized, observing the subjectivity involved in the design process, the dynamics of open systems, the dialogic and polysemic process in collaborative design processes in the context of social innovation, exercising empathy and affectivity. It is understood that social responsibility, assumed by the design student, brings with it personal transformation, openness to the different and the ability to listen actively in any environment. The inevitability of transdisciplinarity in design education is a finding and the encouragement for students to occupy decision-making positions in pedagogical processes is seen as a catalyst for these learnings.

Keywords Social responsibility, Education, Design Autonomy, Complexity.

\section{Responsabilidad social y educación en diseño: autonomía frente a la complejidad de los fenómenos humanos contemporáneos}

Resumen Este trabajo aborda la responsabilidad social en el diálogo con la educación del diseño como una forma posible para que el estudiante desarrolle la autonomía necesaria para resolver los problemas complejos que surgen de los tiempos contemporáneos. A través de la revisión bibliográfica, se examinan las habilidades necesarias para el diseñador que comprende su acción y su papel activo como sujeto en este contexto. Se enfatiza la capacidad de lidiar con las incertidumbres y la complejidad del mundo, observando la subjetividad involucrada en el proceso de diseño, la dinámica de los sistemas abiertos, el proceso dialógico y polisémico en los procesos de diseño colaborativo en el contexto de la innovación social, el ejercicio de la empatía y afectividad. Se entiende que la responsabilidad social, asumida por el estudiante de diseño, conlleva transformación personal, apertura a lo diferente y la capacidad de escuchar activamente en cualquier entorno. La inevitabilidad de la transdisciplinariedad en la educación del diseño es un hallazgo y el estímulo para que los estudiantes ocupen puestos de toma de decisiones en los procesos pedagógicos se considera un catalizador para estos aprendizajes.

Palabras clave Responsabilidad social, Educación, Diseño, Autonomía, Complejidad. 


\section{Introdução}

O processo de desenvolvimento técnico-científico culminou em uma complexificação tanto das relações humanas quanto das relações que conectam um lugar a outro. Dessa forma, hoje não somos capazes de pensar um problema no Brasil como um problema exclusivo deste país, deste governo e das pessoas que aqui habitam. As crises que assolam determinado país possuem causas com origens diversas, que nem sempre podemos identificar claramente, e essas mesmas crises podem reverberar de diversas maneiras (e.g. instabilidades econômicas ou políticas, crises ambientais, sanitárias e abismos sociais) no mundo inteiro (MORIN, 2003).

A economia é guiada pela busca do lucro, e a lógica de competição do mercado coloca o indivíduo em uma relação de competição com o outro, com o que é diferente dele. $O$ individualismo, que traz a responsabilidade pessoal pela sua própria vida, também fortalece o egocentrismo, inibindo as capacidades altruístas e solidárias e desintegrando as comunidades tradicionais (MORIN, 2005b). Essa situação favorece a busca do bem-estar individual como principal e maior, transgredindo o senso de coletividade.

Nossa civilização separa os saberes, ao invés de religá-los a um todo complexo. Separa as pessoas umas das outras, separa o conhecimento da ética, a razão da emoção e também a objetividade da subjetividade. As diferentes ciências também são separadas e compartimentalizadas, dentro dos sistemas educacionais, o que tende a colocar o indivíduo em uma qualificação parcial (técnica) por vezes destituída de responsabilidade e solidariedade na medida em que está separada do seu contexto social e cultural (MORIN, 2003). Dessa forma, o próprio ser humano é objetificado, apassivado, assumindo uma posição fatalista diante de sua realidade (FREIRE, 2019). Assim, não é permitido ao sujeito a visualização de novas formas de mundo e a capacidade de criá-las. Resta o sentimento de desesperança e desilusão.

Dentro deste panorama é importante discutirmos novas formas de ensinar e novas formas de pensar, que nos permitam lidar com as crises próprias da contemporaneidade. Ao mesmo tempo, precisamos de conectar os sujeitos com a sua comunidade, religando os saberes humano, técnico e ambiental, vendo-os como parte de um sistema e agindo uns sobre os outros (MORIN, 2015).

A intenção do presente trabalho é somar à discussão sobre Educação em Design na formação superior, observando a necessidade pulsante de pensarmos novos propósitos e funções para o design, baseadas nas novas necessidades contemporâneas. Procuramos abordar a educação em design que contempla a responsabilidade social, como possível caminho para desenvolver autonomia necessária ao indivíduo para atuar como sujeito na sociedade, buscando o bem-estar tanto individual, quanto coletivo. Admite-se a universidade como um lugar de formação de pessoas, e não apenas de profissionais. 
Serão traçados caminhos que conectam a complexidade, a educação e as práticas de design colaborativo em inovação social. Inicialmente será abordado o design como estratégia para lidar com as incertezas próprias da complexidade do mundo, quando temos designers profundamente preocupados com o contexto humano onde o design aflora e também deflagra acontecimentos, reconhecendo a subjetividade implicada nesse processo. Depois será abordada a responsabilidade social em Design, destacando três características que facilitam o desenvolvimento de autonomia: o contato com diferentes vivências, o trabalho colaborativo e a capacidade de diálogo. Por último, será destacada a transformação pessoal na educação, sendo a compreensão humana e a compreensão do outro, dependentes de uma compreensão de si mesmo, ou seja, para que haja autonomia, é necessário um comprometimento pessoal com a mudança de si.

\section{Complexidade e design: aprender a lidar com incertezas}

A complexidade, ou a forma de pensar complexa, como posta por Edgar Morin (2007), nos ajuda tanto ter uma compreensão do mundo de forma abrangente, possibilitando-nos enxergar a ligação entre diferentes instâncias (política, social, ética, religiosa, ambiental, econômica) quanto perceber a teia que liga os diferentes fenômenos. A forma complexa de ver o mundo também abre possibilidades de diálogo com esse mundo, que, além da ordem, também é composto por acasos e anomalias, que podem explodir na forma de caos e desordem.

Entende-se que qualquer contexto (e.g. uma escola, comunidade, um país, ou qualquer lugar de inserção de um projeto de design) deve ser visto como um sistema aberto, dialogando com os sistemas externos a ele. O princípio sistêmico (ou organizacional) nos permite ligar o conhecimento de um sistema ao "todo" do qual faz parte. Todo sistema aberto só pode ser explicado quando o percebemos dentro de um panorama maior. Dessa forma, a própria organização de um sistema complexo tem, ao mesmo tempo, aspectos de ordem e desordem em sua constituição. Um organismo vivo, como o corpo humano, é composto por células que estão em constante mutação e é esse exato processo de morte e regeneração de células que permite a sua sobrevivência, a sua ordem. Ao mesmo tempo, o que permite a sobrevivência desse organismo é sua abertura ao mundo externo e sua interação com ele. Essa relação do sistema com o ambiente é antagônica e ao mesmo tempo complementar. Assim, para que um sistema complexo continue existindo, ele precisa estar constantemente dialogando com o meio ambiente que é estranho a ele, que por um lado o tensiona e o confronta, mas por outro lado também o completa. Dessa forma, não podemos pensar um sistema sem uma relação dialógica entre ideias ou paradigmas que se excluem e ao mesmo tempo, se complementam. 0 pensamento complexo funciona abraçando a ambiguidade e a desordem como parte da complexidade do mundo (MORIN, 2003b, 2007). 
Esse desafio que a complexidade trás, também implica no desafio de integrar diferentes saberes, diferentes ciências e campos do conhecimento, e procurar educar pessoas que tenham a aptidão para contextualizar esses conhecimentos. Segundo o autor, ideias e teorias não podem ser vistas separadas do seu contexto cultural, que determina significações específicas e que podem até mesmo serem inversas em diferentes culturas. As ideias separadas de um contexto que as nutre e que substancialize seu significado, corre o risco de se tornarem inúteis, causando um estado de ignorância e cegueira. Teorias precisam ser repensadas, regeneradas, para que se mantenha sua complexidade, sem serem degradadas em simplificação (MORIN, 2003a, 2005a). Por isso, repensar os sistemas educacionais para que formem pessoas capazes de ver o mundo e o ser humano de forma complexa é imperativo neste momento.

É importante que fique clara a diferença dos conceitos de "sobreviver" e "viver". Sobreviver contempla a satisfação das necessidades básicas: comer, dormir, etc. Viver significa ter a dignidade para desenvolver suas qualidades e aptidões. Dentro dos espaços de formação superior vemos, muitas vezes, um grande enfoque em habilidades técnicas que preparam o aluno para ser um consumidor cada vez melhor, sendo esse espaço educacional um lugar de preparação para a sobrevivência na selva do mercado, mas não necessariamente capacitados para lidar com um futuro incerto ou com os desafios que o presente nos revela. Viver significa ter autonomia para enfrentar esses problemas e não se sentir imobilizado por eles. Autonomia demanda capacidade para lidar com a incerteza e desordem que é própria da complexidade do mundo (MORIN, 2015).

Ao definir o que seria essa incerteza, Morin refere-se ao caráter caótico da história humana: criações e destruições de impérios, progressão e regressão de economias, etc. A história humana tem determinantes sociais e econômicos muito fortes, mas que podem sofrer desvios, através de acontecimentos inesperados. Portanto, não há leis na história, pelo contrário, existe um fracasso em determinar acontecimentos, eliminar acidentes e submetê-la a um determinismo econômico-social do progresso (MORIN, 2003a).

Quando tomamos decisões, neste contexto, entendemos que a ação “...uma vez iniciada, entra num jogo de interações e retroações no meio em que é efetuada, que podem desviá-la de seus fins e até levar a um resultado contrário ao esperado" (MORIN,2003a, p. 61). As consequências de uma ação são imprevisíveis, por isso, a complexidade pede uma estratégia, que permite a consciência da incerteza e de que qualquer ação é uma aposta.

\footnotetext{
A estratégia (...) é estabelecida tendo em vista um objetivo; vai determinar os desenvolvimentos da ação e escolher um deles em função do que ela conhece sobre um ambiente incerto. A estratégia procura incessantemente reunir as informações colhidas e os acasos encontrados durante o percurso (MORIN, 2003a, p. 62).
} 
Quando olhamos o design através das lentes da complexidade, conseguimos compreender que a própria complexidade do mundo impede o design de ser algo menos do que "fragmentado, híbrido, mutante" (JULIER, 2000 apud MOREIRA et al, 2016, p. 356) onde podemos ver várias ambiguidades, várias realidades diferentes coexistindo dentro de um mesmo campo e em contextos educacionais diferentes. Essa é uma qualidade que precisa ser abraçada na educação superior em design e na prática pedagógica dos professores. A complexidade confere ao design um caráter que vai além da técnica e do material, impelindo-o a misturar-se e conectar-se com diferentes campos. Essa relação interdisciplinar abre o caminho para abordagens colaborativas (OCKERSE, 2012) permitindo que o design possa servir como estratégia para dialogar com a complexidade.

Ao falar sobre os desafios trazidos pelo século XXI, Findeli frisa a necessidade de pensar um novo propósito para o design e para essa prática, tendo a educação em design um papel crítico no que diz respeito ao ensino de novas habilidades que permitem o enfrentamento de problemas contemporâneos.

\footnotetext{
O [novo] papel do designer é entender a morfologia dinâmica de um sistema, sua "inteligência". Não se pode agir sobre um sistema, somente no interior de um sistema; não se pode agir contra a inteligência de um sistema, somente encorajar ou desencorajar um sistema a seguir seu curso [...] (FINDELI, 2001, p. 10, tradução nossa).
}

Em um processo de design, dessa forma, determinado sistema sairia de um estado A, para um estado B, deslocando a lógica de solução, material e concreta, para um estado transitório, mais harmônico, dentro de um processo que é dinâmico. Para que o designer consiga trabalhar dentro desta dinâmica, é preciso um tipo de inteligência visual que vai além da estética, percebendo a representação adequada do conteúdo, estrutura e tendências desse sistema. Um projeto nunca abrange somente um sistema. Ele abrange vários contextos: técnico, biofísico, social e simbólico (FINDELI, 2001).

A visualização de um sistema nunca será definitiva e perfeita, sendo sempre composta de erros e falhas, entendendo que esses sistemas funcionam através de pessoas, que possuem suas próprias demandas, habilidades e compreensões sobre determinado problema. Dessa forma, a nova inteligência visual que o designer precisa, consiste em perceber a subjetividade própria de um contexto onde o fator humano (em toda a sua complexidade), está inserido. Dentro da lógica complexa, o designer teria seu foco voltado para o agir, ao invés do fazer, entendendo que, em certos momentos, o não fazer também pode ser considerado agir (FINDELI, 2001).

A habilidade primordial que precisa ser aprendida pelos designers é a capacidade de lidar com pessoas de forma aberta e colaborativa, ensinando habilidades e também aprendendo a fazer design com pessoas que não são especialistas em design. 
Responsabilidade social e educação em design: autonomia frente à

complexidade dos fenômenos humanos na contemporaneidade

\section{Responsabilidade social em design: aprender a dialogar no trabalho colaborativo}

A discussão sobre responsabilidade social dentro do campo do design foi trazida à tona na década de 70, quando os vícios industriais do American Way of Life já mostravam seu lado sombrio: o excesso de lixo gerado pela obsolescência programada, a desigualdade social, e o uso desenfreado de recursos naturais que não contemplava os impactos ambientais. 0 design, quando usado como uma ferramenta corporativa, seria o grande responsável pelo desequilíbrio social, ambiental e econômico (PAPANEK, 1973). Ainda de acordo com o autor, os designers estariam vivendo dentro de uma "bolha" criativa, saindo das universidades conhecendo muito pouco sobre outras áreas do conhecimento e incapazes de compreender os impactos sociais e ambientais do design.

Pensar a educação em design significa pensar não só o propósito do design no mundo (FINDELI, 2001), mas também que tipo de pessoas estão sendo formadas para o mundo. Papanek (1973) destaca a necessidade de um design integrador e compreensivo, cuja transformação - do profissional e da forma de se fazer design - estaria na educação, colocando o aluno em contato direto com os usuários dos produtos, integrando essas pessoas como parte do processo de projetar, trazendo o espírito criativo do design para fora dos espaços dos escritórios e das escolas de design. Portanto, uma educação em design com responsabilidade social implica, primeiramente em colocar os alunos em contato com diferentes vivências.

Hoje podemos ver uma pluralidade de metodologias colaborativas em design, onde os usuários dos produtos agem como parceiros no processo criativo, somando as suas experiências às capacidades do designer (design participativo), onde o designer é catalisador de mudanças sociais, em um engajamento cívico dentro de um processo que envolve um público ativo, e envolvido em diálogos concretos sobre possibilidades de um futuro (codesign) (PAES e ANASTASSAKIS, 2016). A inexatidão própria do design como disciplina, exige que os processos e resultados de design estejam sempre abertos a debates e a discussões, caráter esse cuja importância se torna ainda maior quando, em um contexto de conectividade através da internet, existem muitas possibilidades de propostas colaborativas (BUCHANAN apud PAES e ANASTASSAKIS, 2016).

Dentro de um período de transição marcado pelo crescimento de evidências sobre os limites do mundo e crescimento da conectividade, o design também cresceu e se expandiu, saindo de uma lógica de produto e adotando uma aproximação "human-centered" (centrado no ser-humano): processo que projeta soluções para problemas sociais, ambientais e políticos" (MANZINI, 2016). Quanto mais percebemos as questões humanas em um contexto de design, maior a demanda de processos participativos, investigando com profundidade as capacidades e necessidades das pessoas envolvidas e as dinâmicas sociais nas quais vivem (MANZINI, 2016). É interessante perceber como o design como estratégia, cada vez mais, pede a capacidade de dividir informa- 
ções com pessoas de outros contextos, sabendo dialogar com elas, tendo um olhar empático sobre diferentes situações que podem não ser familiares ao designer. Cada vez mais o design se assemelha à uma pedagogia, habilitando mais e mais pessoas a pensarem de forma criativa.

$O$ autor traz o design inserido na inovação social, processo de mudança social que alcança novas configurações sociais de forma inovadora pela recombinação criativa de processos já existentes dentro de um contexto.

Essa mudança pode vir de cima (especialistas em design, ativistas políticos, etc.), como também pode ser uma iniciativa espontânea de pessoas e comunidades diretamente afetadas por essa inovação. $O$ designer agindo dentro de um contexto de inovação social pode ter o papel de iniciador, impulsionador, auxiliador, fortalecedor ou replicador. Em suma, o designer entra com uma "caixa-de-ferramentas" (habilidades ou formas de pensar) para ajudar as comunidades criativas interessadas em mudar determinado contexto, também com o intuito de promover mudanças que visam o desenvolvimento autônomo das mesmas. Essas comunidades são formadas por pessoas que se empenham em inventar, aumentar e gerir soluções viáveis para novas formas sustentáveis de viver, de forma cooperativa (MANZINI, 2014).

$\mathrm{Na}$ inovação social, entende-se que a mudança social só acontece dentro de um espaço de colaboração, muitas vezes recombinando tradições, saberes, ferramentas e habilidades já existentes dentro daquele contexto de forma inovadora, contando com seus próprios recursos, sem esperar uma solução que venha do governo ou uma grande mudança na economia e na infraestrutura das instituições (ibidem). Vale ressaltar que, embora designers possam estar engajados em iniciativas que promovam inovação social, esse não é um processo que necessita de especialistas em design, por outro lado, que vê o design como um tipo de ação que pode ser feito por não-designers. Sendo assim, o design vem para facilitar a inovação social, quer ela já exista ou não.

Nesse cenário, Ezio Manzini (2011) vê a escola de design e o polo de pesquisa da universidade como um lugar de oportunidade, um "recurso social" poderoso na transição para uma forma de vida mais sustentável, já que a universidade é o local onde os novos especialistas em design são formados e onde podemos nutrir novas formas de pensar o design. Além disso, a formação de designers competentes para o futuro, exige o envolvimento dos estudantes com problemas, oportunidades e métodos de design que fomentem processos de inovação, que hoje parecem radicalmente novos e que ainda envolvem um pequeno número de minorias ativas, ao mesmo tempo, equipando-os para um futuro onde as modalidades de design que emergem hoje, se tornarão padrão.

o design centrado na pessoa e que está envolvido em um processo de inovação social, pede uma abordagem dialógica, onde todos os atores envolvidos estão dispostos a ouvir e se modificarem. Mesmo que, momentaneamente, haja tensões e problemas, existe o objetivo de chegar a um lugar comum. Essa é a principal característica dos processos colaborativos. A habilidade de ouvir, de ter empatia, em uma abordagem dialógica é crucial 
para o designer tanto quanto a habilidade de propor suas próprias ideias e visões da forma mais apropriada (MANZINI, 2016). Saber dialogar exige coerência entre o que é dito e o que é feito. Isso significa que precisa haver um sentimento de disponibilidade, de abertura ao outro, ao invés da vontade de tentar convencer o outro a pensar como si.

\footnotetext{
[...] não é falando aos outros de cima para baixo, sobretudo, como se fôssemos os portadores da verdade a ser transmitida aos demais, que aprendemos a escutar, mas é escutando que aprendemos a falar com eles. [...] Até quando, necessariamente, fala contraposições ou concepções do outro, fala com ele como sujeito da escuta de sua fala crítica e não como objeto de seu discurso (FREIRE, 1996, p. 113).
}

A ação colaborativa, é um processo de educação mútuo: de um lado existe por parte do designer uma ação de provocação para instigar uma nova forma de ver determinado contexto ou situação e de outro, pelos atores do contexto de ensinarem ao designer diferentes realidades e formas de mudança. Paulo Freire destaca a importância do diálogo em um contexto periférico:

[...] chegando a favelas ou a realidades marcadas pela traição a nosso direito de ser, pretende que sua presença vá se tornando convivência, que seu estar no contexto vá virando estar com ele, é o saber do futuro como problema e não como inexorabilidade. [...] meu papel no mundo não é só o de quem constata o que ocorre, mas também o de quem intervém como sujeito de ocorrências (FREIRE, 1996, p. 76-77).

Com essas palavras, compreendemos que responsabilidade social denota ação. Em se tratando de design, como visto até aqui, responsabilidade significa um comprometimento com as consequências sociais de um projeto, sendo capaz de ver a complexidade dos fenômenos humanos, entendendo que contextos periféricos, onde as crises sociais (violência, fome, falta de moradia e saneamento básico) são apenas sintomas locais de crises também globais. Compreende-se também que responsabilidade implica em estar presente em determinado contexto, de forma afetiva, ser parte da vivência daquele contexto. Esse agir responsável, em determinada situação, não tem a intenção de certeza ou solução absoluta de um conflito ou problema, mas admite que a realidade é um sistema em constante mudança, e que os erros e percalços são parte do processo. Como explica Paulo Freire (1996), aprender a tomar decisões implica em assumir as consequências que estão implicadas nesse ato. 
[...]Não há decisão a que não se sigam efeitos esperados, pouco esperados ou inesperados. Por isso é que a decisão é um processo responsável. [...] Uma pedagogia da autonomia tem de estar centrada em experiências estimuladoras da decisão e da responsabilidade (p. 106-107).

Desta forma, conclui-se que é importante assumirmos a inegável importância da responsabilidade social como foco principal na educação em design, onde a criatividade está presente como necessidade, encorajando essa posição de decisão, ao estimular o contato dos estudantes com diferentes realidades. Essa decisão pedagógica permite aos alunos exercitar uma forma de ver o mundo dentro das relações antagônicas e complementares próprias da complexidade, aperfeiçoando a capacidade de diálogo em processos criativos e colaborativos e favorecendo o amadurecimento da autonomia.

\section{Educação transformadora: aprender a mudar a si através do outro}

Se entendemos o indivíduo como sistema (ou organização) complexo(a), entendemos que o sujeito só pode ser constituído na relação com o meio que o cerca. Não só o indivíduo depende da sociedade, a cultura, para se desenvolver e gerar novos conhecimentos, como a própria cultura depende da interação entre os indivíduos para mudar, se regenerar e se renovar. Essa interação nos permite compreender que, na verdade, a relação do indivíduo com a sociedade acontece de forma recursiva. 0 indivíduo está na sociedade, assim como a sociedade está no indivíduo através das normas e experiências sociais, a linguagem, a cultura. Esse conhecimento é dotado de vários sujeitos que se produzem e se interferem. Entre todas as instâncias produtoras do conhecimento há uma unidade recursiva complexa, ao mesmo tempo em que há relação hologramática ${ }^{1}$ entre todas elas, ou seja: cada uma delas contém as outras em sua composição. Isso significa dizer que a ideia mais simples é dotada de complexidade, pois é produto dessas retroações que formam a complexidade sociocultural. (MORIN, 2005a) O conhecimento sobre a complexidade humana "...faz parte do conhecimento da condição humana; e esse conhecimento nos inicia a viver, ao mesmo tempo, com seres e situações complexas" (MORIN, 2003a, p. 49).

Morin (2015) trata da importância da compreensão humana para a compreensão da complexidade do mundo. Essa compreensão vai além de uma compreensão intelectual ou objetiva, que comporta uma explicação, reunindo dados sobre a pessoa. A compreensão humana, subjetiva, requer abertura para o outro como alguém semelhante a mim na sua humanidade e, ao mesmo tempo, diferente de mim na sua singularidade pessoal e/ou cultural. 
A compreensão do outro e sobretudo uma compreensão complexa do outro, requer tanto a compreensão objetiva, quanto a compreensão subjetiva, pois visa a captar seus aspectos singulares e também globais, percebendo também o contexto onde essa pessoa está inserida. Ao mesmo tempo, essa compreensão complexa do outro exige a compreensão de nós mesmos, reconhecendo nossos limites e insuficiências.

Quando vemos a sociedade e indivíduo como indivisíveis, nos permitimos olhar para o outro, para o diferente, com um olhar de solidariedade, e nos colocarmos como responsáveis pelo destino desse outro e da humanidade como um todo (MORIN, 2005b, 2015). Dessa forma, não podemos falar dos aspectos transformadores do design e da educação em design, seu impacto social, sua capacidade de integrar atores em um processo colaborativo, sem pensarmos em uma transformação também do indivíduo, que precisa assumir a responsabilidade social como uma escolha sua, o que exige uma vontade de transformação pessoal. A educação formal que visa a responsabilidade social e a própria intenção pedagógica em despertar o olhar para o outro é, em si, como qualquer ação dentro da complexidade, incerta, pois não se pode forçar ninguém a assumir essa responsabilidade.

"Cada um vive para si e para outro de maneira dialógica, ou seja, ao mesmo tempo, complementar e antagônica. Ser sujeito é associar egoísmo e altruísmo" (MORIN, 2005b, p. 21). Quanto mais apto ao diálogo com o outro, mais abertura ao diferente, maior a capacidade de transformação do indivíduo. A análise de si comporta uma introspecção junto à análise do outro, somando a autocrítica com a crítica do outro, confrontado o olhar amistoso com o olhar inamistoso. "Somente a autocrítica pode dar-nos uma consciência de nossas insuficiências e da nossa segurança" (MORIN, 2005b, p. 96).

Essa abertura requer a percepção do outro como igual a mim na sua humanidade, e diferente de mim, nas suas particularidades biológicas, culturais e sociais. Por isso a responsabilidade com o outro está diretamente relacionada com a autonomia, que é um processo que nunca cessa, enquanto houver essa disposição para o confronto de si pelo outro, tendo em mente que somos seres inacabados (FREIRE, 1994). A afirmação de Paulo Freire vai ao encontro de Edgar Morin, quando afirma que: 


\begin{abstract}
A responsabilidade, contudo, deve ser irrigada pelo sentimento de solidariedade, ou seja, de pertencimento a uma comunidade. [...] o indivíduo é irresponsável se o considerarmos como um joguete de forças anônimas e obscuras (sociológicas, ideológicas, pulsionais) e responsável se o considerarmos como sujeito dotado de uma relativa autonomia (MORIN, 2005b, p. 100).
\end{abstract}

A responsabilidade social exige a percepção de que as pessoas dependem umas das outras para mudar a situação atual e criar realidades mais harmônicas. $\mathrm{O}$ ato responsável também assume a aposta, e os possíveis erros e problemas que a ação pode desencadear, pois não somos totalmente culpados pela interpretação pelos outros dos nossos atos e nem pela consequência deles (MORIN, 2005b). No ato responsável, os erros e percalços são abraçados, por serem eles os impulsos à mudança de estratégias de ação e de comunicação com o outro. São necessárias, portanto, iniciativas educacionais que encarem os erros e falhas como naturais, no processo de aprendizado.

Ser designer com responsabilidade social exige uma predisposição à transformação pessoal, que acontece somente quando existe uma conexão afetiva com as pessoas que participam do processo, se colocando como parte daquilo, da melhor forma possível. Como já foi pontuado, trabalhar de forma coletiva é um processo de educação mútua e, em se tratando de inovação social em realidades periféricas, de exclusão, cenários muitas vezes diferentes do cotidiano do designer, é necessário um "querer bem" (FREIRE, 1994) ao outro, reconhecendo sua humanidade, suas potências e estando aberto a aprender com elas.

\title{
Considerações finais
}

Educar novos designers para serem capazes de mudar realidades complexas, cada vez mais exige que a educação em design aconteça dentro de um contexto de transdisciplinaridade, abraçando o conhecimento da biologia, antropologia, sociologia, psicologia, entre outras áreas. 0 design, assim como qualquer outro campo de conhecimento, cresce e se modifica pela abertura a outros saberes (que podem também não ser acadêmicos). A capacidade de adaptação do design e o apelo estético e comunicativo inerente à área são características que temos a nosso favor no caminho para esse crescimento. Essa evolução exige que a formação do designer não seja um processo enclausurado dentro das paredes da universidade e da "bolha" do design. Também é necessária uma autocrítica do próprio campo, abandonando velhas práticas que já não funcionam, estando aberto às mudanças de fora e também trazendo de volta práticas pedagógicas que estavam pre- 
sentes no início da educação em design, na Bauhaus, onde o conhecimento de mundo, a sociologia e filosofia eram consideradas tão importantes quanto as disciplinas de projeto e de práticas artísticas. A teoria precisa ser colocada em prática, de forma ativa, com experiências no "mundo real" e procurando uma maior ligação entre a academia e o contexto social e cultural onde a instituição está inserida.

Uma educação que coloca o aluno em uma posição de decisão é importante para a autonomia do indivíduo, independente de qual for sua atuação profissional depois de graduado, tendo em mente que a universidade (e a educação formal como um todo) precisa ser um espaço de formação de pessoas, primeiramente, que atuam como sujeitos na sociedade e não somente objetos passivos, vítimas de acontecimentos sociais (FREIRE, 1994), meros profissionais. "Ensinar exige a corporificação das palavras pelo exemplo" (FREIRE, 1994, p. 34). Para isso, o professor socialmente responsável precisa estar também presente de forma afetiva na sua prática pedagógica diária, assumindo essa intenção de formação de alunos capacitados para atuarem como sujeitos na sociedade.

A mudança do design, da educação em design e da educação formal como um todo, depende de pessoas que estejam neste mesmo engajamento, e isso inclui alunos, professores, funcionários, coordenadores, pessoas que tem posição de liderança na universidade. Porém, não podemos esperar a iniciativa das instituições. A inovação social acontece quando as pessoas se engajam de forma coletiva, usando os recursos que tem ao seu dispor.

As pessoas, nas instituições onde há ensino de design, devem ser catalisadores dessas mudanças. Como recursos, podemos destacar as oportunidades que a universidade possui, os contatos com a comunidade não acadêmica: pesquisa e extensão, eventos universitários abertos a todos, além das próprias ferramentas do design já citadas, entre outras. A universidade deve ser um espaço onde as carências sociais que tangenciam a instituição são discutidas e usadas como brechas de aprendizado. Mais do que tudo, é necessário que os professores não se deixem imobilizar por um horizonte político pouco promissor, e exercitem a visão do futuro como problema a ser resolvido e não como inexorabilidade (FREIRE, 1994). 


\section{Referências}

FINDELI, Alain. Rethinking Design Education for the 21st Century: Theoretical, Methodological, and Ethical Discussion. Design Issues, Londres, v. 17, n. 1, p. 5-17, 2001. Disponível em: http://www.mitpressjournals.org/doi/10.1162/07479360152103796. Acesso em: 2 jul. 2019. FREIRE, Paulo. Pedagogia da Autonomia. 33. ed. São Paulo: Paz e Terra, 1996. MORIN, Edgar. A cabeça bem-feita: repensar a reforma, reformar o pensamento. 8. ed. Rio de Janeiro: Bertrand Brasil, 2003.

MORIN, Edgar. Educar na Era Planetária. 3a. ed. São Paulo: Cortez Editores, 2003.

MORIN, Edgar. Ensinar a viver: manifesto para mudar a educação. Porto Alegre: Sulina, 2015. MORIN, Edgar. Introdução ao pensamento complexo. 3. ed. Porto Alegre: Sulina, 2007. MORIN, Edgar. 0 Método 2: A vida da vida. Porto Alegre: Sulina, 2005.

MORIN, Edgar. O Método 6: Ética. Porto Alegre: Sulina, 2005.

MANZINI, Ezio. Design Culture and Dialogic Design. Design Issues, Londres, v. 32, n. 1, p. 1-5, 2016. Disponível em: https://www.mitpressjournals.org/doi/pdf/10.1162/DESI_a_00364. Acesso em: 2 jul. 2019.

MANZINI, Ezio. Design schools as agents of (sustainable) change. In: 1ST INTERNATIONAL SYMPOSIUM FOR DESIGN EDUCATION RESEARCHERS 2011, Paris. Anais... Disponível em: http://sigeneration.ca/documents/Designschoolsasagentsofsustainablechange.pdf. Acesso em: 2 jul. 2019.

MANZINI, Ezio. Making Things Happen: Social Innovation and Design. Design Issues, Londres, v. 30, n. 1, p. 57 - 66, 2014. Disponível em: https://www.mitpressjournals.org/doi/ abs/10.1162/DESI_a_00248?journalCode=desi. Acesso em: 2 jul. 2019.

MOREIRA, Mafalda; MURPHY, Emma; MCARA-MCWILLIAM, Irene. The Emergence of an Amplified Mindset of Design: Implications for Postgraduate Design Education. International Journal of Art and Design Education, [s. 1.], v. 35, n. 3, p. 356-368, 2016. Disponível em: https://onlinelibrary.wiley.com/doi/abs/10.1111/jade.12118. Acesso em: 2 jul. 2019. OCKERSE, Thomas. Learn from the core, design from the core. Visible Language, Cincinnati, v. 46., n. 1/2, p. 80-93, 2012. Disponível em: https://www.questia.com/library/journal/1P3-2752821331/learn-from-the-core-design-from-the-core. Acesso em: 2 jul. 2019.

PAES, Larisa; ANASTASSAKIS, Zoy. Reflexões Sobre Processos Colaborativos De Design. In: BLUCHER DESIGN PROCEEDINGS 2016, São Paulo. Disponível em: https://www.proceedings.blucher.com.br/article-details/reflexes-sobre-processos-colaborativos-de-design-24316. Acesso em: 2 jul. 2019.

PAPANEK, Victor. Design for the real world. New York: Bantam, 1973. 